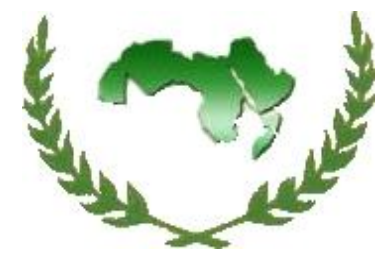

Arab Univ.

J. Agric. Sci.,

Ain Shams Univ.,

Cairo, 15(1), 3 - 16, 2007

\title{
ECONOMIC FEASIBILITY STUDY FOR MUSHROOM PRODUCTION IN SMALL ENTERPRISES
}

\author{
El-Dehemy, Abla ${ }^{1}$, A.A. and M.A. Gad ${ }^{1}$ \\ 1. Central Laboratory for Statistical Analysis Research, Agricultural Research Center, Giza, Egypt
}

[1]

Keywords: Mushroom, Economic Feasibility, Small Enterprise

\begin{abstract}
Many countries are interested in production of Mushroom because of its high nutritive value. In Egypt, production of Mushroom is about $0.06 \%$ of the world production. Therefore, the present study aimed to investigate the economic feasibility of Mushroom production to evaluate the predicted profits in Egypt. The results showed that production of Mushroom significantly increased by 0.15 thousand ton/year. China, U.S.A and Germany are the top producing countries where $46.11 \%$ from the total world production is produced by these countries. The top exporting countries are China, Poland and Ireland since they export $57.67 \%$ from the total world exports of Mushroom. Meanwhile, Germany, Japan, England and U.S.A. are the top importing countries which import about $574.82 \%$ thousand tons/year through (2002- 2004). The study revealed that production of Mushroom is profitable as an enterprise for small investors in Egypt. Total production costs per year is about
\end{abstract}

L.E. 8000. This small project gives two work opportunities and income of L.E. 12 thousand per year. The Internal rate of return of the enterprise is about $35 \%$ and the Payback period is about three years. Mushroom, the simple rate of return on investment is about $36 \%$. The sensitivity analysis indicated that the least Internal rate of return supposing reduction of total income, is about $10 \%$ or increasing the total costs by $10 \%$, the least Internal rate of return reached to $14 \%$. Whereas, simple rate of return on investment was estimated by $24 \%$ which was more than the interest rate in commercial banks that reached $10 \%$. Therefore, This study recommends encouraging young-people enterprises in rural communities in new lands to produce Mushroom, by introducing technical consults, financial facilities for small investors. Also, limiting production and marketing difficulties, improving efficiency of marketing systems. In addition to maximizing production of Mushroom for exporting to the international markets and organizing training courses for spotting light on the economic feasibility of Mushroom to increase number of the investors to produce Mushroom.

(Received November 21, 2006)

(Accepted December 16, 2006)

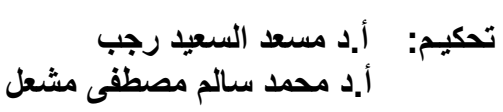

